Asian J Agric \& Biol. 2021(3).

$\mathrm{AJAB}$

DOI: $10.35495 / a j a b .2020 .10 .549$

Original Article

\title{
Evaluation of maize genotypes for resistance to Sitophilus zeamais Motschulsky (Coleoptera: Curculionidae) infestation
}

\author{
Jonathan Siamey ${ }^{1,2}$, Kwame Duodu Ansah ${ }^{2}$, Daniel Ashie Kotey ${ }^{{ }^{*}}$ \\ ${ }^{1}$ CSIR-Plant Genetic Resources Research Institute, Bunso, Eastern Region of Ghana, Ghana \\ ${ }^{2}$ Sunyani Technical University, Sunyani, Ghana
}

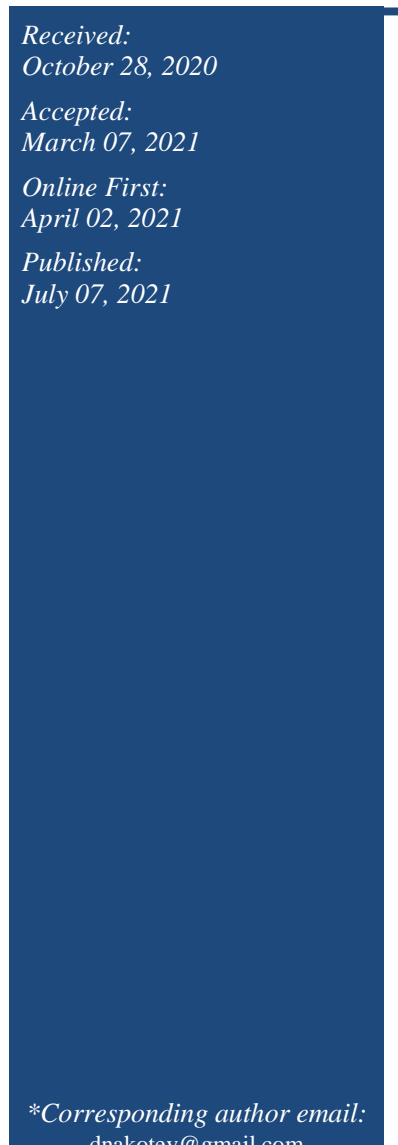

\begin{abstract}
The use of Sitophilus zeamais resistant maize germplasm for breeding new varieties can contribute to reduce hazardous insecticide use on stored maize. This study evaluated six maize genotypes, five genebank accessions (GH2354, GH3239, GH3324, GH3609, GH6182) and one commercial variety (OBATANPA) for resistance to $S$. zeamais infestation. Maize grains were infested with adult weevils and data on number of grains with weevil damage, percentage weight loss, median developmental time and index of susceptibility was collected. Differences in the number of days to first adult emergence between genotypes were not significant $(P>0.05)$. Differences between genotypes for all other parameters evaluated were however significant $(P<0.05)$. Accession GH3609 recorded the most damaged grains $(23.32 \%)$ and the highest $(15.41 \%)$ grain weight loss, whereas OBATANPA recorded the lowest $(9.81 \%)$ damaged grains whilst the lowest weight loss $(8.26 \%)$ was observed in GH6182. The proportion of damaged grains correlated with weight loss $(r=0.96)$ and index of susceptibility $(\mathrm{r}=0.82)$. All evaluated genotypes were susceptible to $S$. zeamais attack. Little research has been conducted to identify $S$. zeamais resistant maize germplasm in Ghana. The results of this study should serve as baseline information in the screening for resistance to $S$. zeamais.
\end{abstract}

Keywords: Accession, Genotypes, Index of susceptibility, Median developmental time, Resistance

\section{How to cite this:}

Siamey J, Ansah KD and Kotey DA, 2021. Evaluation of maize genotypes for resistance to Sitophilus zeamais Motschulsky (Coleoptera: Curculionidae) infestation. Asian J. Agric. Biol. 2021(3): 202010549. DOI: https://doi.org/10.35495/ajab.2020.10.549

This is an Open Access article distributed under the terms of the Creative Commons Attribution 3.0 License. (https://creativecommons.org/licenses/by/3.0), which permits unrestricted use, distribution, and reproduction in any medium, provided the original work is properly cited.

\section{Introduction}

Maize, Zea mays L, is a vital food and cash crop for a significant proportion of subsistence farmers and their families across sub-Saharan Africa (Van den Berg et al., 2015). Infestation of stored maize grain by insect pests and subsequent losses resulting from the feeding activities of such pests remains a significant constraint to increasing production to guarantee food and nutrition security (World Bank, 2011). The maize weevil, Sitophilus zeamais Motschulsky (Coleoptera: Curculionidae) is one of the most economically significant post-harvest constraints to maize storage (World Bank, 2011) in many production areas, particularly in the tropics. The adult weevil bores into and lays eggs on maize kernels both in field and storage 
or at any time it comes into contact with unprotected maize grains. After hatching, larvae feed and pupate inside maize kernels. Infestation of maize kernels results in weight loss and quality (nutritional) deterioration which constitutes a threat to food security especially in developing countries like Ghana (Hill, 1983; Rouanet, 1992). Storage structures as well as physical and chemical properties of the infested maize may influence its susceptibility to damage by $S$. zeamais (Odeyemi and Daramola, 2000). Acording to the World Bank (2011) damage to maize grains is most severe in smallholder farmers' fields and cribs. Estimates of qualitative and quantitative damage to maize grains infested by $S$. zeamais ranges between 20 to $100 \%$ (Nukenine et al., 2002; Muzemu et al., 2013; FAO, 2010).

In Ghana, most maize farmers have been observed to apply broad spectrum insecticides to harvested maize grains prior to or during storage to prevent $S$. zeamais damage (MoFA, 2001). While these insecticides are important tools for the reduction of storage losses due to $S$. zeamais, their repeated use can lead to the emergence of insecticide resistant insect strains, an increase in production and storage costs, contamination of treated grains with toxic insecticide residues and increased risks to insecticide applicators (Asawalam and Hassanali, 2006; Mabbett, 2007) and consumer safety. Although a number of strategies including the use of plant products with insecticidal, anti-feedant or repellent properties have been proposed for the management of $S$. zeamais, adoption and use remains a challenge (Owusu-Akyaw, 1991; Midega et al., 2016). In recent times, research efforts in some maize production areas have focused on sustainable $S$. zeamais management strategies including host plant resistance which involves the breeding and deployment of maize varieties resistant to $S$. zeamais (Abebe et al., 2009). The development of such varieties however relies on the identification of maize germplasm with resistance or tolerance to infestation by the target insect pest (Kotey et al., 2020). Although, there is a large collection of maize germplasm in Ghana, little research has been devoted to identifying $S$. zeamais resistant genotypes for use in maize improvement programmes. This study therefore evaluated five maize accessions from the Ghana genebank against $S$. zeamais infestation.

\section{Material and Methods}

The study was undertaken from May to July, 2019 at the Entomology Laboratory of the Council for
Scientific and Industrial Research - Plant Genetic Resources Research Institute (CSIR-PGRRI), BunsoGhana. Five maize accessions; GH2354, GH3239, GH3609, GH6182, GH3324 from the CSIR-PGRRI and one commercial maize variety, OBATANPA were used for the study. Grains of all the six maize genotypes were subjected to sun-drying for four weeks. After which period the moisture contents of grains of each genotype were determined using an LDS-1G grain moisture meter. Grains with moisture contents above $12 \%$ were further dried until they attained the desired moisture content of $12 \%$. Three hundred (300) unsexed $S$. zeamais adults were obtained from maize grains that were previously infested and introduced into three $750 \mathrm{ml}$ glass jars with $500 \mathrm{~g}$ of untreated maize grains obtained from the market. The adults used for the starter culture were not sexed because previous studies have reported that the sex ratio of Sitophilus spp including $S$. zeamais is approximately, 1: 1 (Richards, 1947; Evans, 1977; Danho et al., 2002). Following the introduction of adult weevils, a muslin cloth with open weaves small enough to prevent $S$. zeamais adults and larvae from escaping but loose enough to allow for unhindered ventilation was used to seal each glass jar to prevent the weevils from escaping or re-infesting other jars. The jars with the introduced weevils were left to stand for 14 days under ambient conditions to allow the weevils to feed and oviposit. After the 14-day period, the introduced weevils were sieved out with a $2.4 \mathrm{~mm}$ mesh. All first filial $\left(F_{1}\right)$ generation adult weevils that emerged from the infested maize sample were placed in new glass jars with a new batch of uninfested maize grains. The resulting $\mathrm{F}_{2} S$. zeamais adults were used in the experiment.

All maize grains to be used for the experiment were evenly spread on a clean plastic tray such that all grains were visible. All grains were closely inspected individually and any grain with signs of infestation or damage including exit/entrance holes signs of boring and chewing were hand-picked and discarded. Maize grain selected as clean were placed in a Wagtech GP120SSF300HYD drying oven and subjected to heat treatment at $54.5^{\circ} \mathrm{C}$ for a period of 30 minutes (Back and Cotton, 1924) to kill insect stages hiding within grains. After grains were removed from the oven, 100 $\mathrm{g}$ batches were weighed into $750 \mathrm{ml}$ glass jars. Ten newly emerged and unsexed adult weevils from the weevil culture described above were randomly picked with a camel's hair brush and used to artificially infest the grains in each jar. After infestation, each jar was 
tightly covered with a muslin cloth and kept under ambient conditions. The introduced weevils were left to feed and oviposit for 14 days following which they were removed by sieving out with a $2.4 \mathrm{~mm}$ mesh. The design of the experiment was Completely Randomized (CRD) with three replications. Thus, there were three jars per maize genotype adding up to a total of 18 glass jars.

After 18 days of infestation, the maize genotypes were sieved daily. The number of days to first weevil emergence and the number of weevils that emerged in each maize genotype were recorded on a daily basis until all F1 progenies had emerged. The number of maize grains with weevil damage symptoms was recorded by closely inspecting all the grains of each maize genotype for signs of weevil damage including grains with exit or ragged holes. The number of damaged grains (bored kernels) in each genotype was used to compute the percentage of grains damaged by $S$. zeamais per each genotype. An Adam equipment electronic weighing balance (Max. capacity $=410 \mathrm{~g}$ ) was used to record the weight of grains of each maize genotype 62 days after infestation when no new weevil emergence was observed. The count and weigh method (Tiongson, 1992) was then used to determine the percentage of weight lost by grains of each maize genotype.

$$
\text { Weight loss }(\%)=\frac{N d *(W u-W d)}{W u *(N d+N u)} * 100 \%
$$

Where $\mathrm{Wu}=$ Weight of undamaged seed, $\mathrm{Nu}=$ Number of undamaged seed, $\mathrm{Wd}=$ Weight of damaged seed, and $\mathrm{Nd}=$ Number of damaged seed.

The median developmental time was determined as the number of days from the middle of oviposition to $50 \%$ adult weevil emergence. The data obtained was used to calculate the index of susceptibility (Dobie, 1974).

$$
\text { Index of susceptibility }=\frac{\log (F 1)}{m d t} * 100 \%
$$

Where $\mathrm{F}=$ total first filial $\left(\mathrm{F}_{1}\right)$ generation emerged and $\mathrm{mdt}=$ median developmental time/period.

Table-1. Susceptibility index

\begin{tabular}{|c|c|}
\hline Dobie's index & Classification of maize genotype \\
\hline$\leq \mathbf{3}$ & Resistant \\
\hline $\mathbf{4 - 7}$ & Moderately Resistant \\
\hline $\mathbf{8 - 1 0}$ & Susceptible \\
\hline$\geq \mathbf{1 1}$ & Highly Susceptible \\
\hline
\end{tabular}

Ten intact grains with no signs of $S$. zeamais infestation or damage were randomly selected from each maize genotype. Standard maize crop descriptors (IBPGRI, 1991) were then used to describe the shape of the upper surface of the selected grains. The length, width and thickness of all ten selected grains were also measured using a pair of digital calipers $(150 \mathrm{~mm})$ and recorded.

Ahrens et al. (1990) have stated that arcsine transformation is generally not recommended for the transformation of percentage data sets having values from 0 to $20 \%$ or 80 to $100 \%$. The same authors have also suggested that for such data sets, the square root transformation is recommended. Square root transformation was therefore performed on all count and percentage data before analysis using GENSTAT (12 ${ }^{\text {th }}$ Edition, The NULL Corporation). Untransformed means are presented in tables. Mean differences were separated using the least significant difference $(\mathrm{LSD})$ at $5 \%($ alpha $=0.05)$. Correlation analysis was performed separately using Microsoft Excel (Microsoft Office, version 10).

\section{Results}

\section{Mean number of days to first adult weevil emergence}

There were no significant differences $(P>0.05)$ in the time (days) to first emergence of adult weevils among the different maize genotypes. The mean number of days to first emergence of $S$. zeamais adults ranged from 24.7 days (accession GH3609) to 35.7 days (accession GH3239). For OBATANPA variety, the mean number of days to first weevil emergence was 26.3 (Table 2). The correlation between days to first emergence of adult weevils and other parameters evaluated ranged from $\mathrm{r}=-0.665$ to 0.339 (Table 4).

\section{Mean percentage damaged grains}

There were significant $(P<0.05)$ differences in the percentage of damaged grains between maize genotypes. The highest percentage (23.32) of damaged grains was recorded in accession GH3609 while the lowest (9.81) percentage was recorded in OBATANPA variety. The percentage of damaged grains of accessions GH2354, GH3239, GH3324 and GH6182 were however not significantly different from that of OBATANPA variety (Table 2). A strong positive correlation $(r=0.957)$ was observed between percentage damaged grains and grain weight loss. 
There was also a strong positive correlation between the percentage of damaged grains and the number of $\mathrm{F}_{1}$ progenies that emerged $(\mathrm{r}=0.811)$ as well as the index of susceptibility $(r=0.822)$ of genotypes (Table 4).

\section{Mean percentage weight loss of maize grains}

There were significant differences $(P<0.05)$ observed among the maize genotypes with respect to percentage weight loss. The lowest mean weight loss was 8.26 (accession GH6182) while the highest mean weight loss was 15.41 (accession GH3609). Differences in weight loss between accessions GH2354, GH3239, GH6182 and OBATANPA variety were not significant (Table 2). It was observed that grain weight loss had a positive correlation with the number of $F_{1}$ progenies that emerged $(\mathrm{r}=0.689)$ as well as the index of susceptibility $(r=0.795)$ (Table 4$)$ of maize genotypes.

Table-2. Mean emergence of weevils, percentage damage and percentage weight loss of maize accessions.

\begin{tabular}{|c|c|c|c|}
\hline Genotypes & $\begin{array}{c}\text { Days To } \\
\text { Emergence }\end{array}$ & $\begin{array}{c}\text { \% Damage } \\
\text { Grains }\end{array}$ & $\begin{array}{c}\text { \% Weight } \\
\text { Loss }\end{array}$ \\
\hline GH 2354 & 30.7 & $14.26 \mathrm{~b}$ & $11.44 \mathrm{bc}$ \\
GH 3239 & 35.7 & $10.59 \mathrm{~b}$ & $9.23 \mathrm{c}$ \\
GH 3324 & 31.3 & $16.45 \mathrm{ab}$ & $13.02 \mathrm{ab}$ \\
GH 3609 & 24.7 & $23.32 \mathrm{a}$ & $15.41 \mathrm{a}$ \\
GH 6182 & 30.0 & $11.05 \mathrm{~b}$ & $8.26 \mathrm{c}$ \\
OBATANPA & 26.3 & $9.81 \mathrm{~b}$ & $8.51 \mathrm{c}$ \\
\hline P-Value & 0.484 & 0.013 & 0.007 \\
F- Value & 0.95 & 4.71 & 5.66 \\
\hline
\end{tabular}

Means within the same column followed by the same alphabets are not significantly different at $P<0.05$.

\section{$F_{1}$ emergence and index of susceptibility}

There were significant $(P<0.05)$ differences in the number of $F_{1}$ progenies that emerged and the index of susceptibility of maize accessions. The highest number of weevil adults that emerged (117.7) was recorded in accession GH3324 while the least number (36.7) was recorded in accession GH6182 (Table 2). Using Dobie's index of susceptibility (Table 1), the six maize genotypes were all scored as susceptible to $S$. zeamais attack. Accessions GH3609, GH3324 and GH2354 were highly susceptible while accession GH3239, GH6182 and OBATANPA were susceptible (Table 3). The index of susceptibility of maize genotypes was strongly correlated $(r=0.733)$ with the number of $F_{1}$ progenies that emerged. Inversely, there was a negative correlation between the time (days) to first emergence of adult weevils, number of $F_{1}$ progenies that emerged $(\mathrm{r}=-0.103)$ and the index of susceptibility $(r=-0.370)$ (Table 4) of maize genotypes.

Table-3. Index of susceptibility and mean number of $F_{1}$ emerged.

\begin{tabular}{|c|c|c|c|c|}
\hline Genotypes & Total $\left(\mathbf{F}_{\mathbf{1}}\right)$ & MDT & DIS. & Susceptibility status \\
\hline GH 2354 & $74.3 \mathrm{~b}$ & 37 & $11.61 \mathrm{bc}$ & Highly susceptible \\
GH 3239 & $66.0 \mathrm{~b}$ & 40 & $10.47 \mathrm{bc}$ & Susceptible \\
GH 3324 & $117.7 \mathrm{a}$ & 37.33 & $12.77 \mathrm{ab}$ & Highly susceptible \\
GH 3609 & $106.7 \mathrm{a}$ & 37.33 & $14.31 \mathrm{a}$ & Highly susceptible \\
GH 6182 & $36.7 \mathrm{c}$ & 37 & $9.71 \mathrm{c}$ & Susceptible \\
OBATANPA & $43.7 \mathrm{c}$ & 36 & $10.46 \mathrm{bc}$ & Susceptible \\
\hline P - Value & $<\mathbf{0 . 0 0 1}$ & - & $\mathbf{0 . 0 1 8}$ & \\
F - Value & $\mathbf{3 1 . 5 5}$ & & $\mathbf{4 . 3 2}$ & \\
\hline
\end{tabular}

Means within the same column followed by the same alphabets are not significantly different at $P<0.05$.

MDT=Median Developmental Time

DIS= Dobie's Index of Susceptibility

Table-4. Correlation coefficients among parameters for maize resistance to $S$. zeamais

\begin{tabular}{|c|c|c|c|c|c|c|c|c|}
\hline & $\begin{array}{c}\text { \#DE } \\
1^{\text {st }} \\
\end{array}$ & $\begin{array}{l}\text { DG } \\
(\%)\end{array}$ & $\begin{array}{c}\text { GWL } \\
(\%)\end{array}$ & $\begin{array}{c}\# F_{1} \\
\text { Emerged } \\
\end{array}$ & IS & Shape & $\begin{array}{c}\text { Length } \\
(\mathbf{m m})\end{array}$ & $\begin{array}{l}\begin{array}{l}\text { Width } \\
(\mathbf{m m})\end{array} \\
\end{array}$ \\
\hline DG (\%) & -0.399 & - & & & & & & \\
\hline GWL (\%) & -0.361 & 0.957 & - & & & & & \\
\hline $\begin{array}{c}\# \mathrm{~F}_{1} \\
\text { Emerged }\end{array}$ & -0.103 & 0.811 & 0.689 & - & & & & \\
\hline IS & -0.370 & 0.822 & 0.795 & 0.733 & - & & & \\
\hline Shape & 0.297 & 0.572 & 0.695 & 0.653 & 0.552 & - & & \\
\hline $\begin{array}{l}\text { Length } \\
(\mathrm{mm})\end{array}$ & -0.665 & 0.020 & -0.648 & -0.333 & $0 . \overline{278}$ & -0.757 & - & \\
\hline $\begin{array}{l}\text { Width } \\
(\mathrm{mm})\end{array}$ & -0.608 & 0.259 & -0.428 & -0.582 & 0.389 & -0.517 & 0.423 & - \\
\hline $\begin{array}{l}\text { Thickness } \\
\text { (mm) }\end{array}$ & 0.339 & 0.270 & 0.067 & -0.270 & $0 . \overline{279}$ & 0.439 & 0.626 & 0.285 \\
\hline
\end{tabular}

\#DE $1^{\text {st }}=$ number of days to first emergence, DG (\%) $=$ percent damaged grains, GWL $(\%)=$ percent grains weight loss, $\# F_{1}$ Emerged $=$ number of $F_{1}$ progenies emerged and IS = index of susceptibility

Table-5. Mean grain shape and size of maize accessions

\begin{tabular}{|c|c|c|c|c|}
\hline Genotypes & Shape & $\begin{array}{c}\text { Length } \\
(\mathbf{m m})\end{array}$ & $\begin{array}{c}\text { Width } \\
(\mathbf{m m})\end{array}$ & $\begin{array}{c}\text { Thickness } \\
(\mathbf{m m})\end{array}$ \\
\hline GH 2354 & 3.4 & 8.19 & 8.49 & 4.77 \\
\hline GH 3239 & 3.1 & 8.9 & 7.99 & 4.35 \\
\hline GH 3324 & 3.6 & 8.48 & 8.24 & 4.59 \\
\hline GH 3609 & 3.4 & 9.68 & 8.34 & 4.2 \\
\hline GH 6182 & 3.2 & 9.11 & 8.7 & 5.01 \\
\hline OBATANPA & 2 & 10.22 & 8.75 & 4.2 \\
\hline
\end{tabular}




\section{Correlation analysis of test genotypes}

Grain shape had a positive correlation with days to first adult weevil emergence, percentage damaged grains, grain weight loss, emergence of $F_{1}$ progeny and index of susceptibility whiles grain size had a correlation coefficient ranging from positive $(\mathrm{r}=$ $0.626)$ to strongly negative $(r=-0.757)$ (Table 4$)$.

\section{Discussion}

Sitophilus zeamais is a destructive insect pest species that constrains the safe and sustainable storage of maize in many sub-Saharan African countries. In this study, the type of maize genotype had no effect on the mean period (days) for the emergence of adult weevils. The early emergence of adult weevils from a maize genotype may be an indication of susceptibility to Sitophilus zeamais attack. Maize genotypes from which adult weevils emerged early may have supported successful laying of eggs and the rapid development of progeny. Inversely, genotypes with a longer period to adult weevil emergence could be an indication of some level of resistance to $S$. zeamais infestation. The delayed emergence of progeny may be attributed to the effect of some physical attributes of the maize grain including hardness or antibiosis resulting from the biochemical composition of grains. These attributes may have reduced oviposition success and progeny production (Garcia-Lara et al., 2004; Siwale et al., 2009). The structure, attractiveness and conduciveness of individual grains of maize genotypes for $S$. zeamais to feed, develop and reproduce on could have also played a role in earlier or delayed progeny emergence. The nature of food on which an insect is reared may therefore affect its rate of growth and development (Ojo and Amoloye, 2016). The resistance to $S$. zeamais infestation has been observed to be associated with protein content, presence of ferulic acid, tryptophan and lysine in maize grains (Abebe et al., 2009; Nhamucho et al., 2017). Maize genotypes with harder grains and high crude protein content have been observed to be resistant to $S$. zeamais infestation (Siwale et al., 2009). Mcmullen et al. (2009) have also suggested that the expression of genes that inhibit proteinase activity is elicited by mechanical injury and insect damage to the grain.

Huang et al. (1998) identified alpha-pinene, an organic compound as being responsible for the anti-feeding and growth inhibitory effects of some maize genotypes against $S$. zeamais. Phenolic acids, structural proteins and diferulates have been reported as the fundamental cell wall components associated with the resistant trait of the maize grain (Abebe et al., 2009; Nhamucho et al., 2017). These components are reported to have a strong negative correlation with parameters of $S$. zeamais susceptibility and a positive correlation with the extent of hardness of the maize grain (Garcia-Lara et al., 2004). Even though grain texture was not evaluated in this study, grain hardness has been observed to be closely related to $S$. zeamais resistance. This is due to the fact that maize genotypes that are resistant to $S$. zeamais have harder kernels and are thus less susceptible to $S$. zeamais damage (Siwale et al., 2009; Nhamucho et al., 2017). In view of the reported effects of biochemical traits on $S$. zeamais infestation, coupling entomological with biochemical screening of maize germplasm may facilitate the identification of promising maize germplasm for breeding $S$. zeamais resistant varieties.

Grain weight loss is a primary parameter for assessing the susceptibility of maize grains to $S$. zeamais. Sitophilus zeamais usually lays more eggs and multiplies faster on grains of susceptible maize genotypes. In the absence of any mitigation strategy therefore, the population of the pest can increase exponentially. The positive correlation observed between grain weight loss and the number of $F_{1}$ progenies that emerged among the evaluated genotypes implies that, the greater the emergence, the higher the rate of feeding. Similarly, the greater the rate of feeding, the more the damage to grains and consequently, the higher the percentage weight loss. In the course of feeding on grains, $S$. zeamais consumes the endosperm and the embryo thereby causing significant reduction in grain weight (Hill, 1983). The strong positive correlation observed between percentage damaged grains and the percentage weight loss among the maize genotypes evaluated concurs with the finding of Nhamucho et al. (2017) who attributed high weight loss in susceptible genotypes to the high maize kernel damage caused by $S$. zeamais. The implication of this is that, grains of susceptible genotypes supported large numbers of weevil larvae, causing high kernel damage and subsequent weight loss compared to resistant genotypes.

According to Keba and Sori (2013) maize genotypes with high $F_{1}$ progeny emergence suffer relatively higher grain damage and grain weight loss than those with low $F_{1}$ progeny emergence. Siwale et al. (2009) have also suggested that the extent of damage to stored maize grains by $S$. zeamais is a function of the length of weevil life cycle and the number of adult weevils 
that emerge. This study shows that high $\mathrm{F}_{1}$ progeny production is associated with an increase in the susceptibility of maize genotypes to $S$. zeamais infestation. It was also observed in this study that a shorter duration between the time of infestation and $F_{1}$ progeny emergence was associated with a high level of susceptibility of maize genotypes to $S$. zeamais infestation. The implication of this is that compared to resistant maize genotypes, there are more weevil generations per unit time in susceptible genotypes than in resistant ones. Thus, for each succeeding weevil generation, there are more weevils per grain of a susceptible maize genotype compared to a resistant one. Derera et al. (2010) have suggested that the percentage damaged grains, the percentage weight loss, the number of emerged $F_{1}$ progenies or the Dobie index of susceptibility can be primary parameters for the evaluation and selection of $S$. zeamais resistant maize germplasm.

\section{Conclusion}

Using Dobie's index of susceptibility, all the accessions in the study were found to be susceptible to S. zeamais infestation; accessions GH2354, GH3609 and GH3324 were identified as highly susceptible while accessions GH3239, GH6182 and OBATANPA variety were identified as susceptible. In evaluating crop germplasm against insect pest incidence, the availability of germplasm with known susceptibility to a target pest is equally as important as resistant/tolerant germplasm. This is because such germplasm serve as a reference standard against which test entries can be accessed. The results obtained from this study can therefore serve as baseline information in the exploration for $S$. zeamais resistant maize germplasm.

\section{Acknowledgement}

The authors will like to gratefully acknowledge the Management and Staff of the CSIR-PGRRI.

Disclaimer: None.

Conflict of Interest: None. Source of Funding: None.

\section{References}

Abebe F, Tefera T, Mugo S, Beyene Y and Vidal S, 2009. Resistance of maize varieties to the maize weevil Sitophilus zeamais (Motsch.) (Coleoptera: Curculionidae). Afr. J. Biotechnol. 8: 5937-5943.

Ahrens WH, Cox DJ and Budhwar G, 1990. Use of the Arcsine and Square Root Transformations for Subjectively Determined Percentage Data. Weed Sci. 38: 452-58.

Asawalam EF and Hassanali A, 2006. Constituents of the essential oil of Vernonia amygdalina as maize weevil protectants. Trop. Subtrop. Agroecosyst. 6: 95-102.

Back EA and Cotton RT, 1924. Relative resistance of the rice weevil, Sitophilus oryza L., and the granary weevil, $S$. granaries L., to high and low temperatures. J. Agric. Res. 28:1043-1044.

Danho M, Gaspar C and Haubruge E, 2002. The impact of grain quantity on the biology of Sitophilus zeamais Motschulsky (Coleoptera: Curculionidae): oviposition, distribution of eggs, adult emergence, body weight and sex ratio. J. Stored Prod. Res. 259266.

Derera J, Pixley K and Giga D, 2010. Appraisal of protocol for the rapid screening of maize genotypes for maize weevil resistance. Afr. Entomol. 18:8-16.

Dobie P, 1974. The susceptibility of different types of maize to post-harvest infestation by Sitophilus zeamais and Sitotroga cerealella, and the importance of this factor at the small-scale farm level, pp. 98-113. In Proceedings of the First Working Conference on Stored Product Entomology. Savannah, Georgia, USA.

Evans DE, 1977. The capacity for increase at low temperatures of several Australian populations of Silophilus oryzae (L.). Aust. J. Ecol. 2: 55-67.

FAO (Food and Agricultural Organization of the United Nations), 2010. Reducing Post-harvest Losses in Grain Supply Chains in Africa: Lessons Learned and Practical Guidelines, pp. 18-19. In Proceedings of an FAO/World Bank Workshop on reducing postharvest losses in grain supply chains in Africa, 1819 March 2010. The FAO, Rome, Italy.

Garcia-Lara S, Bergvinson DJ, Burt AJ, Ramputh AI, Pontones DMD and Arnason JT, 2004. The role of pericarp cell wall components in maize weevil resistance. Crop Sci. 44: 1546-1552.

Hill DS, 1983. Agricultural insect pests of the tropics and their control $2^{\text {nd }}$ ed. Cambridge University Press, United Kingdom.

Huang Y, Hee SK and Ho SH, 1998. Antifeedant and growth inhibitory effects of $\alpha$-pinene on the stored- 
product insects, Tribolium castaneum (Herbst) and Sitophilus zeamais Motsch. Int. Pest Control. 40:18-20.

IBPGRI, 1991. Descriptors for maize. International Maize and Wheat Improvement Center, Mexico City/ International Board for Plant Genetic Resources Institute, Rome, Italy.

Keba T and Sori W, 2013. Differential Resistance of Maize Varieties to Maize Weevil (Sitophilus zeamais Motschulsky) (Coleoptera: Curculionidae) under Laboratory Conditions. J. Entomol. 10: 1-12.

Kotey DA, Siamey J, Okley F, Egbadzor KF and Bissah MN, 2020. Assessment of stem borer incidence on maize accessions and its implications to the search for sources of stem borer resistance. Ghana $\mathrm{J}$. Forestry 36:22-33.

Mabbett T, 2007. Feed your crops and fight the pest: African farming March/April pp. 19-20.

Mcmullen M, Frey M and Degenhardt J, 2009. Genetics and biochemistry of insect resistance in maize, $\mathrm{pp}$ 271-289 In: Bennetzen J, Hake S. (eds.), Handbook of Maize: its Biology. Springer Science + Business Media. Dordrecht, The Netherlands.

Midega CAO, Murage AW, Pittchar JO and Khan ZR, 2016. Managing storage pests of maize: Farmers' knowledge, perceptions and practices in western Kenya. Crop Prot. 90: 142-149.

(MoFA) Ministry of Food and Agriculture, 2001. Agriculture in Ghana. Facts and Figures, Statistics, Research and information Directorate, of the Ministry of Food and Agriculture, Accra, Ghana.

Muzemu S, Chitamba J and Mutetwa B, 2013. Evaluation of Eucalyptus tereticornis, Tagetes minuta and Carica papaya as stored maize grain protectants against Sitophilus zeamais (Motsch.) (Coleoptera: Curculionidae). Agric. Forest. Fisheries. 2: 196-201.

Nhamucho E, Mugo S, Gohole L, Tefera T, Kinyua M and Mulima E, 2017. Resistance of selected Mozambican local and improved maize genotypes to maize weevil, Sitophilus zeamais (Motschulsky). J. Stored Prod. Res. 73:115-124.

Nukenine EN, Monglo B, Awason L, Ngamo LST, Tchuenguem FFN and Ngassoum MB, 2002. Farmer's perception on some aspects of maize production, and infestation levels of stored maize by Sitophilus zeamais in the Ngaoundere region of Cameroon. Cameroon J. Biol. Biochem. Sci. 12: 18-30.

Odeyemi OO and Daramola AM, 2000. Storage practices in the tropics, vol. 1. Food storage problem, $1^{\text {st }}$ ed. Dave Collins Publication. Nigeria, $235 \mathrm{p}$.

Ojo JA and Amoloye AA, 2016. Development and life history of Sitophilus zeamais (Coleoptera: Curculionidae) on cereal crops. Adv. Agric. 2016: 1-8.

Owusu-Akyaw M, 1991. Evaluation of Plant Products for the Control of Cowpea and Maize Storage Insects. In Proceedings of Joint SAFGRAD Research Network Workshop, 8-14 March 1991, Niamey, Niger.

Richards OW, 1947. Observations on grain weevils Calandra (Col. Curculionidae). I General biology and oviposition. Proc. Zool. Soc. Lond. 117: 1-43.

Rouanet G, 1992. Maize. The Tropical Agriculturist, CTA, Macmillan, London, United Kingdom.

Siwale J, Mbata K, Mcrobert J and Lungu D, 2009. Comparative resistance of improved maize genotype and landraces to maize weevil. Afr. Crop Sci. J. 17: 1-16.

Tiongson RL, 1992. Standardised methods for the assessment of losses due to insect pests in storage. In R.L. Semple, P.A. Hicks, J.V. Lozare, and A. Castermans (eds), Towards integrated commodity and pest management in grain storage. Proceedings and selected papers from the Regional Training Course on Integrated Pest Management Strategies in Grain Storage Systems, conducted by the National Post Harvest Institute for Research and Extension (NAPHIRE), June 6-18, 1988, Philippines. REGNET/NAPHIRE publication.

World Bank, 2011 Missing Food: the case of postharvest grain losses in sub-Saharan Africa. Report Number 60371-AFR.

Van den Berg J, Erasmus A and Van Rooyen M, 2015. Maize. 88-118. In G.L. Prinsloo, and V.M. Uys (eds), Insects of Cultivated Plants and Natural Pastures in Southern Africa. Entomological Society of Southern Africa, Hatfield, South Africa.

\section{Contribution of Authors}

Siamey J: Conceived the idea and designed the experiment, data analysis and interpretation, experiment set-up, data collection, manuscript write-up and literature search.

Ansah KD: Literature and manuscript review, manuscript final reading and approval.

Kotey DA: Designed the experiment, data analysis and interpretation, literature and manuscript review, manuscript final reading and approval. 